\title{
PERSONAL AND ORGANIZATIONAL CHARACTERISTICS ANTECEDENTS OF MEANINGFUL WORK
}

\author{
Francesco Tommasi, Andrea Ceschi, \& Riccardo Sartori \\ Department of Human Sciences, University of Verona (Italy)
}

\begin{abstract}
The contribution presents evidence of the role played by personal and organizational characteristics of employees in the experience of meaningful work. As referred to the individuals' experience of value and significance of their work, meaningful work is a critical working phenomenon both for individuals (e.g., individuals' well-being) and organizations (e.g., workers' productivity). Therefore, a large number of studies have tried to understand its antecedents, however, it is still not clear about how and to what extent personal and organizational characteristics are associated with meaningful work. For instance, it is unclear the roles of a higher level of education as well as financial returns or good working conditions (e.g., high level of salary and good health insurance) for the pursuit of meaningful work. The contribution considers such a need for knowledge and aims to understand the antecedent role of personal and organizational characteristics in the experience of meaningful work. 570 Italian employees participated in a cross-sectional study that comprised measures of meaningful work and related facets, as well as questions on personal and organizational characteristics. Data were analyzed via the MANOVAs and results showed significant associations with meaningful work dimensions and personal characteristics, such as education, social class and health as well as organizational characteristics, such as job contract, job sector and salary.
\end{abstract}

Keywords: Meaningful work, personal characteristics, organizational characteristics, individual differences.

\section{Introduction}

In the current turbulent time for the economy in worldwide society, an increase of interest for meaningful work construct and linked factors raised among scholars and authors (Yeoman et al., 2019). The notion of meaningful work refers to the experience and perception of one's work and actions of workers as "particularly significant and holding more positive meaning" (Rosso et al. 2010, p. 95). Therefore, the growing interest among authors from various disciplines is due to the positive implications of meaningful work for workers and organizations (just to mention a few; work engagement, motivation, human flourishing). However, although the amount of literature on meaningful work definitions and conceptualizations, prospects on meaningful work theorization seem to be characterized by an embedded nature of being contested (Yeoman et al., 2019). In the literature, it appears that certain aspects such as personal and organizational characteristics might be associated with certain experience at work, e.g., meaningful work. Indeed, in the existing literature, there is a considerable number of reviews and empirical studies on meaningful work which have expanded our knowledge offering different prospects of research. However, only a few authors have proposed an empirical examination of the antecedent role of personal and organizational characteristics for the experience of meaningful work. For instance, it is unclear the roles of a higher level of education as well as financial returns or good working conditions (e.g., high level of salary and good health insurance) for the pursuit of meaningful work (Bailey et al. 2018; Rothmann, et al., 2019).

The contribution presents evidence of the role played by personal and organizational characteristics of employees in the experience of meaningful work. We have taken into account such need for knowledge on the role of personal and organizational characteristics to understand their antecedent role in the experience of meaningful work.

\section{The present study}

According to the literature, we aimed to address the current gaps of knowledge on meaningful work. Then, we devised a cross-sectional study by the use of an online questionnaire with self-report 
measures. It was submitted online (software LimeSurvey) via email which has been sent by the three researchers to a general population of employees of twelve organizations from the Veneto region, in the North of Italy. 619 emails were sent and only 570 participants voluntary filled in the questionnaire (response rate, 92.08\%). After presenting the aim of the study, participants were asked to sign the informed consent to complete the survey. The compilation of the questionnaire required a total of 5-7 minutes.

We asked participants to report their personal and organizational characteristics. In respect of the personal characteristics, participants were asked to indicate their gender, age, education, religion, marital status, social status, and perceived health status. In respect of the organizational characteristics, participants were asked to indicate their contract, collar (white-, blue- or pink-), financial returns ( 1 = more than 1,000 euros per month, $2=$ less than 1,000 euros per month). In addition, we assessed meaningful work by the use of the second module of the modular questionnaire Meaning in Work (ME-Work) Inventory developed by Schnell \& Hoffmann (2020) which has proven good validity in the German and Italian context (Tommasi et al. under review). The second ME-Work module comprises two main dimensions, meaningful work (i.e., the perception that work is meaningful, Cronbach' $\alpha=.857$ ) and meaningless work (i.e., the perception that work is meaningless comprising a sense of crisis of meaning and void, Cronbach ' $\alpha=.887)$. Both dimensions are assessed by the use of three items per dimension with a 5-points Likert scale of agreement $(1=$ not at all, 2 = totally agree $)$. At the end of the data collection, data were analyzed in order to examine the antecedent role personal and organizational characteristics. We made a series of MANOVAs considering each personal and organizational variable separately per all the dimensions of meaningful work. Such analysis as well as reliability were conducted via the use of SPSS version 22.

\subsection{Results}

570 employees participated in the study (average age, 39.69 years old, $S D=12.54,61.4 \%$, $N=350$ females). As reported in table 1, significant differences were found for personal demographic variables except for gender (i.e., meaningful work $F(1,568)=.219, p=.64$, meaningless work, $F(1,568$ ) $=.30, p=.58$ ), generational cohorts (i.e., meaningful work $F(3,566)=.72, p=.57$, meaningless work, $F(1,568)=2.02, p=.16$ ), marital status (i.e., meaningful work $F(4,566)=1.683, p=.170$, meaningless work, $F(3,566)=2.02, p=.111$ ) and religion (i.e., meaningful work $F(3,566)=2.20, p=.08$, meaningless work, $F(3,566)=2.07, p=.103)$. By contrast, each organizational characteristic showed to be significantly associated with meaningful and meaningless work.

Table 1. Significant associations of meaningful/ meaningless work with personal and organizational characteristics.

\begin{tabular}{|c|c|c|c|c|}
\hline \multirow{2}{*}{ Personal varibales } & \multicolumn{2}{|c|}{ Meaningful work } & \multicolumn{2}{|c|}{ Meaninless work } \\
\hline & $F(\mathrm{dfl}, \mathrm{df} 2)$ & $p$ & $F(\mathrm{df1}, \mathrm{df} 2)$ & $p$ \\
\hline Education & $2.106(8,561)$ & .033 & $2.085(8.561)$ & .035 \\
\hline Health & $3.33(4,565)$ & .01 & $5.57(4,565)$ & .000 \\
\hline Social class & $2.611(5,564)$ & .004 & $3.237(5,564)$ & .000 \\
\hline \multirow{2}{*}{ Organizational variables } & \multicolumn{2}{|c|}{ Meaningful work } & \multicolumn{2}{|c|}{ Meaningless work } \\
\hline & $F(\mathrm{df} 1, \mathrm{df} 2)$ & $p$ & $F(\mathrm{df} 1, \mathrm{df} 2)$ & $p$ \\
\hline Collar & $7.221(2,567)$ & .001 & $3.923(2,567)$ & .02 \\
\hline Contract & $2.595(6,563)$ & .017 & $2.279(6,563)$ & .035 \\
\hline Remuneration & $2.586(3,566)$ & .05 & $6.692(3,566)$ & .000 \\
\hline Job Sector & $6.351(7,562)$ & .026 & $1.217(7,562)$ & .291 \\
\hline
\end{tabular}

High educated, and individuals with a low level of perceived health reported having lower levels of meaningful work. Likewise, within the subgroups of the social class, major differences were found between those who reported being in a higher class, with higher levels of meaningless work. These results are in line with those of the organizational characteristics. White-collar resulted to have a higher level of meaningless work as well as for those who reported having a higher level of financial return, i.e., remuneration. Differences were found also in the case of job sector group where participants who reported to have a job as caregiving, craftsmen and technical protectionists, resulted to have higher levels of meaningful work.

\section{Discussion}

In the recent book by Yeoman et al. (2019), the role played by individual and organizational diversity in the experience of meaningful work represents one of the current theoretical boundaries as well as new frontiers of research. Indeed, Hofmeister (2019) noted that the current empirical 
examinations in the field of studies on meaningful work have rarely taken into account such personal and organizational characteristics that might be associated with meaningful work experiences. In this vein, Rothmann et all (2019) proposed a map of the research frontiers on the so-called individual diversity in the experience of meaningfulness. They showed how differences among individuals in meaningful work might be related to their personal differences such as age, religion, marital status, social status and health. Likewise, organizational differences such as work contract, financial returns and occupation types might affect individual working experiences. Therefore, Rothmann et all (2019) proposed to address the current gap of knowledge regarding meaningful work and individual diversity by supporting the use of empirical examination to be used to study and examine such relations.

In the present contribution, we have tried to briefly summarize the associations between employees' personal and organizational characteristics in their experience of meaningful and meaningless work. The evidence of the present paper supports the current perspectives on individual differences in meaningful work. As noted, only a few examples of studies have proposed empirical examination of such differences while a large amount of theoretical discussion are presents. For instance, Lips-Wiersma et all (2016) have found significant differences regarding collar characteristic where pink-collar employees showed a higher level of meaningful work. Likewise, Weeks and Schaffert (2019) have proposed empirical examinations of generational differences, however, no significant differences have been found as in our study. Other authors explored the role of financial returns revealing that employees with a low paid job would find meaning beyond financial reward $(\mathrm{Hu} \& \mathrm{Hirsh}, 2017)$. Our results confirmed previous evidence and expand by adding information about the role of health, social status, education and contract. Indeed, in the respect of gender, generational differences, job sector and collar, our results confirm previous evidence. That is not the case of marital status and religion which are usually predictive of higher levels of meaningful work in the case of believers and partnered (Oelberger, 2019; Lips-Wiersma \& Morris, 2009). In respect of health, social status, education and contract, our results offer a piece of knowledge in regard of the Rothmann et all (2019) model of individual diversity, suggesting possible further explorations.

\section{References}

Bailey, C., Yeoman, R., Madden, A., Thompson, M., \& Kerridge, G. (2019b). A Review of the Empirical Literature on Meaningful Work: Progress and Research Agenda. Human Resource Development Review, 18(1), 83-113.

Hofmeister H. (2019). Work Through a Gender Lens: More Work and More Sources of Meaningfulness. In R. Yeoman, K. Bailey, A. Madden, \& M. Thompson (Eds.), The Oxford Handbook of Meaningful Work (pp. 302-326). Oxford University Press, Corydon, UK.

Hu, J., \& Hirsh, J. B. (2017). Accepting lower salaries for meaningful work. Frontiers in Psychology, $8(\mathrm{SEP}), 1-10$.

Lips-Wiersma, M., \& Morris, L. (2009). Discriminating between "meaningful work" and the "management of meaning." Journal of Business Ethics, 88(3), 491-511.

Lips-Wiersma, M., Wright, S., \& DIK, B. (2016). Meaningful work: differences among blue-, pink-, and white-collar occupations. Career Development International, 21(5), 534-551.

Rosso, B. D., Dekas, K. H., \& Wrzesniewski, A. (2010). On the meaning of work: A theoretical integration and review. Research in Organizational Behavior, 30(C), 91-127.

Rothmann, S., Weiss, L. A., \& Redelinghuys J. J. (2019). Cultural, National, and Individual Diversity and their Relationship to the Experience of Meaningful Work. In R. Yeoman, K. Bailey, A. Madden, \& M. Thompson (Eds.), The Oxford Handbook of Meaningful Work (pp. 429-446). Oxford University Press, Corydon, UK.

Schnell, T., \& Hoffmann, C. (2020). ME-Work: Development and Validation of a Modular Meaning in Work Inventory. Frontiers in Psychology, 11, 3405.

Tommasi, F., Ceschi, A., \& Sartori, R. (2020). Viewing Meaningful Work Through the Lens of Time. Frontiers in Psychology, 11.

Tommasi, F., Sartori, R., Ceschi, A., \& Schnell, T. (under review). The Meaning in Work Inventory: 875 Validation of the Italian Version and its Association with Sociodemographic Variables.

Weeks, K. P., \& Schaffert, C. (2019). Generational Differences in Definitions of Meaningful Work: A Mixed Methods Study. Journal of Business Ethics, 156(4), 1045-1061.

Yeoman, R., Bailey, C., Madden, A., \& Thompson, M. (2019). The Oxford Handbook of Meaningful Work (1st ed.). Oxford University Press, Corydon, UK. 